\title{
PHILOSOPHICAL PERSPECTIVES ON IMAGINATION IN THE WESTERN TRADITION
}

Amy Kind

Claremont McKenna College

for The Cambridge Handbook of the Imagination edited by Anna Abraham

\begin{abstract}
Philosophers in the Western tradition have both theorized about imagination and used imagination in their theorizing about other matters. In this chapter, I first provide a brief overview of philosophical theorizing about imagination with a special focus on its relation to other mental states such as belief and perception. I then turn to a discussion of the methodological role that imagination has played in philosophy. I here focus on the imaginability principle, i.e., the claim that the imaginability of a given scenario entails that such a scenario is in some sense possible. Relying on this kind of principle, philosophers have used imagination to justify theories in domains such as philosophy of mind, metaphysics and ethics.
\end{abstract}

Keywords: imagination, belief, perception, modal epistemology, thought experiments, imaginability, conceivability, possibility

Number of words - Total: 7399 (Main text: 6648 + References, notes, etc.: 751)

Philosophers in the Western world have long theorized about imagination - about what it is and how it is to be distinguished from related mental states. But such philosophers have also long relied upon imagination in their theorizing about other matters - that is, imagination itself has played an important methodological role for philosophers. In this chapter, I focus on these two topics in an effort to provide an introduction to, and an overview of, philosophical perspectives on imagination within the Western tradition. Moreover, as one can only cover so much in an essay of this sort, my focus here is almost solely on the Western analytic tradition. ${ }^{1}$

\section{Philosophical Theorizing About Imagination}

Consider Sophie, an eight-year-old girl who is visiting Paris for the first time, and who has just taken the lift to the summit of the Eiffel Tower. She is both excited and a little bit scared. She believes, correctly, that she is well over 300 meters above the ground. She believes, incorrectly, that she is atop the tallest building in the world. As she enjoys the warmth of the sun on her skin and hears the distant sounds of the vehicular traffic below, she looks out at the city and takes in the magnificent view. Catching sight of various landmarks such as the Arc de Triomphe and the Grand Palais, she remembers her visits there earlier in the week. Finally, caught up in the sheer magic of the moment, she imagines a friendly dragon appearing suddenly alongside the observation deck, and she then imagines that the dragon invites her to climb aboard its back and gently flies her all the way down to the ground.

\footnotetext{
${ }^{1}$ Philosophical perspectives on imagination from the eastern tradition are covered in the chapters by Ram-Prasad and Klein. While there are various other aspects to philosophical investigations into imagination in the Western tradition that will unfortunately be left out here, many of these will be covered in other chapters of this Handbook. To give just one example, though I don't here discuss the role that imagination has played in philosophical aesthetics, this is taken up in the chapter by Davies.
} 
While there's much to think about philosophically when considering all of the different aspects of this brief snapshot of Sophie's mental life, for our purposes what's most important are the similarities and differences between the last mental activity mentioned - her imaginative exercises - and all that's been described previously. We'll here focus primarily on two specific comparisons: first, between imagination and belief and next, between imagination and perception.

\section{Imagination and Belief}

Consider the proposition the gorillas have escaped from the Los Angeles zoo. There are many different attitudes that one might take towards this proposition. One might believe that the gorillas have escaped from the Los Angeles zoo, desire that the gorillas have escaped from the Los Angeles zoo, fear that the gorillas have escaped from the Los Angeles zoo, and so on. In addition to these other attitudes, however, one might also imagine that the gorillas have escaped from the Los Angeles zoo. Along with mental states like belief, desire, and fear, philosophers thus generally treat imagination as a propositional attitude.

In discussions of propositional attitudes, philosophers often characterize them in terms of their direction-of-fit. Beliefs aim at the truth. In forming our beliefs, we take ourselves to be representing the world correctly. That's not to say that all of our beliefs are true, of course. Recall that Sophie believes falsely that the Eiffel Tower is the tallest building in the world. But when we discover that one of our beliefs is false, we generally think that it should be discarded, that is, we think that we should change our minds to conform to the truth. Beliefs are thus said to have mind-to-world direction of fit. Desires, on the other hand, do not aim at the truth. In forming our desires, we do not take ourselves to be representing the world correctly. Rather, we are representing the world as we want it to be. The discovery that some desired state of affairs is not actually the case thus does not suggest that the desire should be discarded. Unlike with beliefs, where we aim to conform our mind to the world, with desires, we aim to conform the world to our mind. Desires are this said to have world-to-mind direction of fit.

What, then, about imagination? Does imagination have mind-to-world or world-to-mind direction of fit? At first glance, it doesn't seem to fit well into either category. ${ }^{2}$ Unlike beliefs, imaginings need not aim to represent the world as we take it to be, nor are they appropriately described as true or false. But they also need not aim to represent the world as we want it to be. On further thought, however, we can see that there is a way in which imaginings might be said to be belief-like with respect to direction-of-fit. ${ }^{3}$ In line with a distinction drawn by Shah and Velleman (2005), we might distinguish between attitudes that treat their contents as true and attitudes that treat their contents as something that is to be made true. Imaginings, like beliefs and unlike desires, treat their contents as true - not actually true, of course, but true for the purposes of the relevant imaginative exercise. In the context of her imaginings while atop the Eiffel Tower, for example, Sophie regards it as true that the

\footnotetext{
${ }^{2}$ Indeed, some philosophers have denied that imagination has a direction of fit (e.g., Humberstone, 1992).

${ }^{3}$ Recently, some philosophers have argued that there is also a desire-like kind of propositional imagining (Currie and Ravenscroft 2002; Doggett and Egan 2007. According to proponents of this view, just as we can make believe that something is the case, we can also make desire that something is the case. Whether there really is such a phenomenon as desire-like imagining has been the subject of considerable debate. For an overview, see Kind (2016).
} 
friendly dragon has invited her to climb aboard his back. In this way, she aims to conform her imagining to the (imaginary) world she is representing rather than aiming to have that world conform to the representational states in her mind.

But while imagination shares with belief its direction of fit, our discussion thus far has already suggested an important way in which imagination differs from belief, namely, with respect to its aim. As we have noted, belief aims at truth. Indeed, this is generally taken to be constitutive of belief, i.e., part of its very nature. Imagining, in contrast, need not aim at truth. That's not to say that imaginings can never be true, nor is it to say that they can never be aimed at the truth. Not every imagining is as fanciful as Sophie's. The zookeeper searching for the escaped gorillas may well try to imagine where they have gone, and in doing so, she will be aiming to get things right. Likewise for the interior decorator who employs her imagination in an effort to determine what configuration of furniture will work best for the space she is designing or the guidance counselor who employs her imagination in an effort to discern what the troubled teenager in her office is feeling. These kinds of imaginative exercises employ what Kind and Kung (2016) call the instructive use of imagination. Yet even though instructive uses of imagination show us that imagination can aim at truth, it is differentiated from belief by the fact that it does not do so by nature.

Is there something that imagining, by its nature, does aim at? One natural suggestion invokes possibility. In aiming at truth, belief aims at what's actually true, i.e., what's true in the actual world. Analogous to this, we might take imagination to aim at what's possibly true, i.e., what's true in some possible world. This connection between imagination and possibility has led many philosophers to think it can play an important role in modal epistemology, that it can provide us with epistemic access to possibility the way that perception provides us with epistemic access to actuality. We return to this issue below when we turn to the philosophical employment of imagination.

The difference in aims between imagination and belief connects to another important way that they differ, namely, with respect to their relation to action. Someone who believes that it's raining outside will typically put on a raincoat or take an umbrella when they leave the house. In contrast, someone who imagines that it's raining outside will not typically take actions of these sorts. That's not to say that imagining is entirely disconnected from action. In the context of pretense, for example, someone who imagines that it's raining may well go get an umbrella. But their imagining may also lead to a different kind of action - that of pretending that they're holding an umbrella - and this is not the kind of action that would likely be taken by someone who believes that it's raining. The fact that imagination and belief have different relations to action is often captured by saying that imagination and belief have different functional profiles, or that they play different functional roles (e.g., Nichols, 2004).

The functional profiles of imagination and belief are not entirely different, however. Here we will take note of just two important similarities. First, our emotional reactions to events that we imagine often mirror our emotional reactions to events that we believe have actually occurred. Imagining a scary scenario can prompt fear, and imagining a tragic scenario can prompt sadness. Perhaps the most obvious cases come from consideration of our emotional responses to fiction, as when a reader cries upon reading the death scene of a beloved character. Second, the inferential profile of imagination 
often mirrors the inferential profile of belief. ${ }^{4}$ Someone who believes they are playing tennis against Serena Williams will likely infer that the ball will be coming at them with a great degree of force; someone who imagines they are playing tennis against Serena Williams will likely also imaginatively infer that the ball will be coming at them with a great degree of force. As this point also shows, there are generally important interactions between our beliefs and our imaginings. What we believe can affect what we imagine. For example, it's because I believe that Serena Williams has a powerful shot that, when I imagine playing tennis against her I also imagine that the ball will be coming at me with a great degree of force. Likewise, what we imagine can affect what we believe. When two tennis players who have never faced each other before are about to play in the Wimbledon final, I might engage in various imaginative exercises in an effort to determine who will win.

Finally, it's worth noting that several philosophers have recently claimed that the philosophical orthodoxy that treats belief and imagination as two distinct attitudes is mistaken. Rather, belief and imagination should be seen as two different ends of a continuum, and there can be intermediate states that are belief-imagination hybrids. Though this view has several prominent proponents (Currie and Jureidini 2004; Egan 2008; Schellenberg 2013), it is at present still a minority position.

\section{Imagination and Perception}

In discussing the contrast between belief and imagination, we focused on propositional imagining. Not all imaginings seem propositional in nature, however. In addition to imagining that the gorillas have escaped from the zoo, one might also simply imagine the gorillas themselves. This kind of imagining is often referred to as objectual imagining.

When characterizing objectual imagining, philosophers often take it to involve the production of mental imagery. "Imagery" is here meant in an expanded sense so as to capture not only visual imagery but also auditory imagery, tactile imagery, and so on. One locus of disagreement in contemporary philosophical discussions of imagination concerns the precise relationship between imagination and mental imagery. Most philosophers agree that the production of mental imagery is insufficient for some mental exercise to be an exercise of imagination, since mental imagery can also be involved in memory. More controversial is the necessity claim: While some philosophers have claimed that mental imagery is essential to imagination (e.g., Brann, 1991, p. 5; Kind, 2001), others claim that imagination can occur without mental imagery (e.g., Walton, 1990; Van Leeuwen, 2013, Stock 2017). Van Leeuwen, for example, argues:

When I imagine, on reading Lord of the Rings, that elves can live forever, I'm fictionally imagining a proposition that I couldn't imagine using mental imagery. It would take too long. (2013, p. 222)

This kind of example can be generalized. Philosophers generally assume that we engage with works of fiction by imagining the text. Relying on this assumption, Stock notes that "some fictional passages

\footnotetext{
${ }^{4}$ For discussion supporting this claim, see Currie and Ravenscroft 2002, pp. 12-13, and Weinberg and Meskin 2006, pp. 178-180. In a recent discussion of imagination, Kathleen Stock has recently argued that there are some situations - most notably with respect to our engagement with fiction - that imagination does not share the inferential profile of belief; see Stock 2017, pp. 175-182.
} 
describe wholly abstract and nonexperienceable states of affairs, which therefore could not be sensorily or phenomenally imagined." (2017, p. 25) In support of this claim, she points specifically to the abstract descriptions of a mathematical system laid out by Borges in his short story, "Tlön, Uqbar, Orbis Tertius," but there are presumably lots of similar examples.

Of course, there are various responses that can be made by the defender of the necessity claim (see, e.g., Kind 2001), and we can't hope here to be able to adjudicate the debate. Note, however, that all of these purported examples of imageless imagination concern propositional imaginings. Thus, while the claim that imagination is always imagistic in nature is highly controversial, the claim that objectual imagination is always imagistic in nature is considerably less so. ${ }^{5}$ For this reason, it's perhaps unsurprising that objectual imagining is often referred to as imagistic or sensory imagination.

Just as propositional imagining can be usefully understood in comparison with belief, objectual imagination can be usefully understood in comparison with perception. Objectual imaginings are often characterized in terms of the various sensory modalities, in that we speak of visual imagination, auditory imagination, and so on. These modifiers point to similarities between objectual imagination and perception, most notably, to phenomenological similarities. The experience of visually imagining a gorilla feels something like the experience of seeing a gorilla - and if you do a particularly good job of imagining the gorilla, it may seem a lot like the experience of seeing a gorilla. The same point holds true for the other sensory modalities. Auditorily imagining the gorilla's grunts resembles the experience of hearing the gorilla's grunts.

The phenomenological similarity is further highlighted by the fact that imagination can be mistaken for perception. Someone who is especially caught up in an imaginative episode might take themselves to be seeing what they are really imagining. Interestingly, there is some evidence that perception can be mistaken for imagination as well. In a famous experiment from the early $20^{\text {th }}$ century, subjects who were seeing a very faint image of a banana projected on a screen took themselves to be imagining the banana rather than perceiving it (Perky 1910; for further discussion and examples, see Currie and Ravenscroft 2002, pp. 72-73).

These sorts of cases seem rare, however. Despite the phenomenological similarities between imagination and perception, we can almost always tell whether we are engaged in an instance of perceiving or imagining - and indeed, we can do so both effortlessly and spontaneously. To convince us of this point, Sartre suggests that we each consult our own inner experience. As he reports of his own inner experience, "I am seated, writing, and see the things around me. Suddenly I form an image of my friend Peter. All the theories in the world are helpless against the fact that I knew, the very instant of the appearance of the image, that it was an image." (1936/1962: 96) For Sartre, this is best explained by the fact that objects we perceive seem to have a sense of presence that is lacked by objects that we imagine; on his view, the object of imagining is presented to us as absent. (see, e.g., Sartre 1940/2010) 14). Hume offers a different sort of explanation for how we can so easily discriminate our imaginings from our perceptions. On his view, sensory impressions typically seem to have a "degree of force and

\footnotetext{
${ }^{5}$ That's not to say that this claim about objectual imagination is universally accepted. For example, Alan White has suggested that one can one can "as easily imagine a difficulty or an objection as ... an elephant or a bus. But only for the latter would the presence of imagery be at all plausible." (White 1990, pp. 88-89)
} 
vivacity" that imaginings lack (Hume 1739/1985, p.). ${ }^{6}$ Hume also invoked considerations of force and vivacity to characterize the phenomenological difference between imagination and memory.

In addition to these phenomenological differences between imagination and perception, there is at least one other important dimension of difference between them, namely, their relation to the will. Given that there are no gorillas in my immediate vicinity, I cannot make myself see an actual gorilla right now, no matter how hard I try. Granted, there are things I can do to facilitate my seeing an actual gorilla. I can go to the zoo or to an animal sanctuary, or I can take a trip to Uganda or somewhere else that gorillas exist in the wild. But I cannot come to see a gorilla simply by an act of will. Matters are different with respect to imagination. Generally speaking, all I need to do to imagine a gorilla is to decide to do so. As this suggests, imagination is under an agent's control in a way that perception is not.

To say this, however, is not to imply that an agent has complete and unconditional control over her imaginings. As Christopher Peacocke has noted, "it is a common experience for visual or auditory imaginings to come to a thinker wholly unbidden - they may even interrupt his thinking." (Peacocke 1985, p. 26) Someone who is bored at work might find herself imagining the beautiful beaches of Hawaii, while someone who is hungry might find herself imagining her favorite chocolate soufflé. Moreover, not only might these imaginings arise without any conscious effort on the imaginer's part, but it might even be the case that the imaginer is powerless to stop imagining them once they have started:

Often after seeing a particularly gruesome murder scene in a horror movie, I keep imagining the murder again and again. In such a case, I usually want the imagining to stop, I might even will myself to stop it, but I typically find myself quite powerless to stop the imagining. Analogously, after awakening to a catchy tune on the radio, the tune often runs through my head for quite awhile; I might even be unable to keep from imagining it, in this way, all day long. (Kind 2001, p. 91)

Having traced these similarities and differences between imagination and perception, l'll close this section by noting one more consideration about these two mental activities that has been important philosophically. In discussing the relation between belief and imagining, we noted that there are important interactions between them; what we believe can affect what we imagine, and what we imagine can affect what we believe. Perhaps unsurprisingly, there are also important interactions between imagination and perception. Writing in the $19^{\text {th }}$ century, Immanuel Kant saw imagination as responsible for synthesizing and transforming raw perceptual inputs into unified and continuous wholes. Within his system, then, imagination is fundamentally involved in every perceptual experience; as he put it, " "imagination is a necessary ingredient of perception." (A120; for discussion see Strawson 1970) Working within a broadly Kantian spirit, Church has recently argued that imagination makes possible our experience of objectivity: it's because we actively imagine alternative perspectives of the objects we're perceiving that we experience them as objective entities. (Church 2010, pp. 648-649) Finally, imagination has been invoked to explain cases of amodal completion. When someone sees a cat standing on the other side of the picket fence, the cat is visually experienced as a continuous, complete entity even though various parts of its body are hidden by the fence posts. To explain how we are able

\footnotetext{
${ }^{6}$ For concerns about the use of the notion of vivacity or vividness in this context, see Kind 2017. For additional discussions of the phenomenology of imagining, and how that phenomenology compares to and contrasts with perception, see Kind forthcoming, McGinn 2004, and Kriegel 2015.
} 
to have a unified experience in these sorts of cases, philosophers such as Nanay (2010) have claimed that we represent the occluded parts by way of imagination.

\section{Philosophical Employment of Imagination}

Over the past several decades, imagination has been called upon to do explanatory work in a great variety of philosophical contexts. To name just a few of these contexts: imagination has been thought to play a role in fiction and our engagement with it (Walton 1990; Currie 1990; Stock 2017), counterfactual reasoning (Byrne 2005), our ability to predict and explain the behavior of others (Goldman 2002), scientific discovery (Polanyi 1966/2009), scientific modelling (Toon 2012), and so on. In addition to relying on the notion of imagination in these various contexts, however, philosophers have themselves put their imaginative capacities to use in their own philosophical theorizing. In this section, we discuss the key role that imagination has long played - and continues to play - in the development of philosophical theories and the arguments for such theories.

To start, we need to return to an issue we touched upon briefly above: the connection between imagination and possibility. As Hume famously wrote in his Treatise on Human Nature, "Tis an establish'd maxim in metaphysics, that whatever the mind clearly conceives includes the idea of possible existence, or in other words, that nothing we imagine is absolutely impossible" (1739/1985, p. 32). Of course, many of the scenarios that we imagine are physically impossible. We can imagine a talking mirror, or a flying broomstick, or a goose who lays golden eggs - all of which are impossible given the scientific laws that govern our world. But, so Hume's thought goes, even if these scenarios are physically impossible, the fact that they are imaginable shows that they are logically possible. Though they may violate the laws of physics, if they are imaginable, then they must not violate the laws of logic.

This principle, that whatever can be imagined is possible, is often referred to by Hume scholars as his conceivability principle, but given Hume's identification of conceiving and imagining, one might just as reasonably think of it as his imaginability principle - and that's how l'll refer to it here. ${ }^{7}$ In the course of the Treatise, Hume goes on to use his imaginability principle to justify many of the conclusions that he draws. To give just one example, in arguing against the proposition whatever has a beginning has also a cause of existence, Hume relies on the fact that the idea of a cause and the idea of a beginning of existence is separable in imagination. The fact that they can be separated in imagination shows that "the actual separation of these objects is so far possible, that it implies no contradiction nor absurdity" (1739/1985, p. 80). He thus concludes that the original proposition must be false.

The underlying form of Hume's argument looks something like this:

1. Scenario $S$ is imaginable.

2. If a scenario is imaginable then it is possible. (The imaginability principle.)

3. Therefore, scenario $S$ is possible.

4. But if scenario $S$ is possible, then theory $T$ is false.

5. Therefore, theory $\mathrm{T}$ is false.

\footnotetext{
${ }^{7}$ That Hume equates conceiving and imagining was evident in the quoted passage above. As we will see below, not all philosophers treat these two mental activities as equivalent.
} 
Arguments with this general structure have been widely used by philosophers across a variety of different subfields - from philosophy of mind to metaphysics to ethics. In the remainder of this section, we will explore the philosophical reliance on imagination by looking at specific examples of this kind of argumentation in more detail. First, we will survey a few common exemplars of this basic form of argument drawn from debates about the nature of mind. We will then consider the plausibility of the imaginability principle in more detail. In doing so, we will also discuss the relationship between imagination and conception.

\section{Imaginability arguments}

At the heart of philosophy of mind lies a debate between two different theories of the nature of mind - physicalism, a view that sees mental processes as reducible to physical processes, and dualism, a view that see mental processes as something over and above the physical. According to the dualists, even if we see a perfect correlation between physical processes and mental processes in actuality, that would not establish the truth of physicalism. Take some mental process $\mathrm{M}$ that is perfectly correlated with some physical process $P$. Even the existence of the perfect correlation does not show that it's impossible for $\mathrm{M}$ to exist without $\mathrm{P}$. Though all actual occurrences of $\mathrm{M}$ are correlated with $\mathrm{P}$, it may still be possible for $\mathrm{M}$ to exist in absence of $\mathrm{P}$ - or even to exist in the absence of any physical process whatsoever. This possibility, claims the dualist, is incompatible with physicalism (e.g., Gertler, 2007). But how do we know that this is really a possibility that needs to be ruled out? Here the dualists employ their imagination - and ask that we all employ our imagination - via the consideration of various hypothetical scenarios known as thought experiments.

Several different thought experiments have been put forward in the literature. Most of these scenarios owe in some way to the insights of $17^{\text {th }}$ century French philosopher Descartes. Often considered to be the father of dualism, Descartes famously proposed in his Meditations that we could conceive of the mind existing without the body. In this Cartesian spirit, Brie Gertler has recently proposed a thought experiment concerning disembodiment (2007). Gertler asks her readers to pinch themselves, consider the pain that results, and then consider whether they can imagine themselves experiencing that very pain while disembodied. If we can imagine experiencing that very pain in the absence of any brain states, indeed any physical states altogether, then in line with Hume's imaginability principle, it would be possible for that very pain to exist in the absence of any physical states. Hence, physicalism would be false.

A different dualist thought experiment that has recently occupied considerably philosophical attention concerns zombies, although not the type that populate Hollywood movies! In his book The Conscious Mind, David Chalmers introduces the notion of a philosophical zombie - a being who is functionally, behaviorally, and even microphysically identical to its human 'twin' but who is entirely lacking in phenomenally conscious states. To use a locution made famous by Thomas Nagel (1970), there is nothing that it is like to be a zombie. Though the zombie can think to itself, "That's a beautiful yellow tulip" or "This brownie has a rich chocolatey flavor," the zombie does not have a phenomenal experience of yellowness or chocolatiness. But given that the zombie and its human twin are microphysically identical, and given that the human has phenomenally conscious states, those states must be something over and above the physical. Thus, if zombies are possible, then it looks like physicalism is false. In defense of the claim that zombies are indeed possible (and here it may be helpful 
to remember that the relevant sense of possibility is logical possibility), dualists point to the fact that they can be coherently imagined.

Another influential thought experiment offered to support dualism concerns a hypothetical color scientist named Mary and has hence become known as the Mary case. As described by Frank Jackson, who first proposed the thought experiment in a paper published in 1982, Mary is a scientist who has spent her entire life in a black and white room and who has never had color sensations of any sort. While inside the room, by way of textbooks and lectures, and so on, Mary learns absolutely everything that color science has to teach - and we are supposed to imagine that Mary lives at some point in the future when color science has been completed. Now imagine that one day Mary is released from her black and white room and is shown a ripe tomato. Upon having the experience of a red sensation for the first time, what happens? In imagining this case, most people have the strong intuition that Mary learns something new. Though she knew all the physical facts about color while she was in the room, she didn't know what seeing red was like. The imaginability, and hence possibility, of this scenario is usually taken to show that the physicalist story about color leaves something out, i.e., it is taken to show that physicalism is false (Jackson 1982).

Outside of philosophy of mind, imaginability arguments have been used to support claims about the nature of personal identity (see, e.g., Parfit 1984), the nature of knowledge (see, e.g., Gettier 1963), the moral permissibility of abortion (see, e.g., Thomson 1971), and the configuration of a just society (see, e.g., Rawls 1971), to give just a few examples among many. Though in some of these contexts the reliance on claims about imaginability is made explicit, in other cases the role of imagination has not always been fully fleshed out.

\section{The Imaginability Principle}

Although imaginability arguments are common in philosophical contexts, there is considerable disagreement about their efficacy. Criticisms of such arguments tend to take two different (but related) lines of attack. On the first line, worries are raised about whether the scenario proposed is really imaginable. On the second line, worries are raised about whether the imaginability of a given scenario really entitles us to draw conclusions about possibility. ${ }^{8}$

To see one example of a worry of the first sort, consider the response the staunchly physicalist philosopher Daniel Dennett has given to the Mary case. In his view, those who think that Mary will learn something new when she leaves her black and white room have not really imagined what they were instructed to imagine. Indeed, if one really were to imagine that Mary knew all the physical facts about color before leaving the room - and not just lots and lots of them - one would be led to see her as having a very different reaction to her encounter with the ripe tomato, namely, she would have been able to predict perfectly in advance what her experience would be like (1991, pp. 398-400).

\footnotetext{
${ }^{8}$ Additionally, worries are also sometimes raised about whether the possibility of a given scenario really entitles us to the further conclusions that are drawn. For example, in the debate about zombies, some opponents of Chalmers' argument dispute whether the logical possibility of zombies is really inconsistent with physicalism. As these worries do not relate directly to imagination, we will not consider them here.
} 
This sort of worry presents the proponent of the imaginability principle with a further problem. The imaginability principle is silent about what conclusion should be drawn in cases where a scenario is unimaginable. The principle under consideration claims only that imaginability implies possibility, and not that unimaginability implies impossibility. But when we have disputes about whether a given scenario is imaginable or not, how are such disputes to be settled? For example, if one person claims to be able to imagine a philosophical zombie and another person claims not to be able to do so, we need some guidance as to how the dispute should be settled. The imaginability principle itself has nothing to say on this score.

In addressing this problem, the proponent of the imaginability principle might first note that not everyone is equally skilled with respect to their imaginative capacities. We see this very clearly in cases of scientific discovery. It's precisely because a scientist like Einstein was able to imagine scenarios that were previously considered unimaginable that he was able to advance our understanding of spacetime. It thus seems that we should judge whether a scenario is imaginable on the basis of the best imaginers perhaps even ideal imaginers - rather than on the basis of ordinary, potentially flawed imaginers. The problem is that this simply pushes the issue back a step, for now we are faced with the task of determining who counts as an ideal imaginer.

However ideal imagination is specified, it must take into account not only one's imaginative capabilities, but also how well placed one is to engage in an imagining concerning a given subject. Someone might be an excellent imaginer, yet because of their ignorance of certain facts, they might make imaginative mistakes. To use an example drawn from Patricia Churchland, someone who does not know much about thermodynamics might think they can imagine "a possible world where gases do not get hot, even though their constituent molecules are moving at high velocity." (1998, p. 39) Given that temperature is identical to mean molecular kinetic energy, however, it seems that something must have gone awry in the imaginative process. To get around this problem, the proponent of the imaginability principle might try to restrict the relevant imaginings to those that are clear, where clarity requires one to have adequate grasp of the concepts being employed in the imagining. But of course, this too might seem just to push the issue back a step, for we are now faced with the task of determining what counts as having an adequate grasp of the relevant concepts.

Returning to Churchland's example, however, note that one could draw a different moral from the apparent imaginability of the non-heated gases scenario. Instead of concluding that something has gone wrong with the imaginative process, one might grant that such a scenario is imaginable, even clearly, and even by an ideal imaginer, and instead deny that we should draw any conclusions about possibility from claims about what's imaginable. Such a move constitutes the second of the two lines of attack against the imaginability principle that we distinguished at the start of this section.

In supporting this second line of attack, one might point to relatively uncontroversial cases of imagining the impossible. Consider the famous picture Ascending and Descending by M.C. Escher. ${ }^{9}$ In this drawing, Escher depicts a group of monk-like figures on a circular staircase. For every ascending monk, it appears that if he continues climbing the staircase, he will return to his starting point without ever having to descend (and likewise, every descending monk can apparently return to his starting point

\footnotetext{
${ }^{9}$ Many of Escher's drawings are reproduced in Hofstadter (1979). In addition to Ascending and Descending (p. 12), see also Relativity (p. 98) and Drawing Hands (p. 690). Tidman (1994) also discusses Escher drawings to make a similar point.
} 
without ever having to ascend). It seems uncontroversial that one cannot eternally climb a staircase without making upward progress, i.e., that such a staircase is impossible. But it also seems uncontroversial that one can imagine such a staircase - after all, one can simply imagine the staircase as depicted in the Escher drawing. In this kind of case, there don't seem to be any grounds to suggest that the imagining is not sufficiently clear, or that it would only be produced by someone whose imagination is not fully ideal. The Escher-imagining thus suggests that we can imagine the impossible and, as a result, that the imaginability principle must be false - or at least, it must be significantly restricted. ${ }^{10}$

Cases like this have suggested to some philosophers that we should look to conceiving, rather than imagining, as the mental capacity that can provide us with a guide to possibility (e.g., Tidman 1994),. Although Hume equated imagining and conceiving as we saw above, many other philosophers treat them as distinct mental activities. Descartes, for example, differentiated them on the grounds that imagination is an imagistic capacity and conception is an activity of pure understanding. More recently, Balcerak Jackson (2016) has argued that imagination and conception are different kinds of perspectivetaking. While imagining takes up the perspective of the subject as the subject of phenomenal experiences, conceiving takes up the perspective of the subject as the subject of rational belief.

The question of whether conceivability entails possibility is beyond the scope of this essay. ${ }^{11}$ But it's worth noting that many of the problems that arise for the imaginability principle will re-arise for the conceivability principle. For example, just as ignorance may affect what we can seem to imagine, so too will it affect what we can seem to conceive. In response to Descartes' reliance on conceivability in his arguments for dualism, Arnauld famously argued in the Fourth Set of Objections printed with the Meditations that someone who is ignorant about geometry may take themselves to be able to imagine a right triangle for which the Pythagorean does not hold (Descartes 1641/1986, pp. 109). In response, Descartes attempted to restrict the relevant conceivings to those that are "clear and distinct" (Descartes 1641/1986, pp. 110-111), but here again, there is a difficulty assessing how this criterion is meant to be employed.

Despite the worries raised about the imaginability principle, philosophers continue to rely on imagination in their philosophical theorizing, and it is hard to see how it could be entirely excised from philosophical methodology. Given that philosophical theories need to address the merely possible along with the actual, and given that we cannot directly perceive possibilities, imagination seems to be an indispensable part of theoretical development and justification. Perhaps for this reason, many philosophers discussing the imaginability principle take imagination to be only a fallible or prima facie guide to imagination (see, e.g., Balcerak Jackson 2016). Here it may be useful to compare imagination to visual perception. There are some cases where visual perception is unreliable, e.g., when the objects being perceived are very small or very far away, when it is dark, when the perceiver is under the influence of hallucinogenic drugs, and so on. That perception is in this way fallible, however, does not prevent us from relying on it. Though it may occasionally lead us astray, visual perception is still a very good guide to the nature of reality. In a similar way, though there may be cases in which imagination leads us astray, we can still rely on it as a guide to possibility.

\footnotetext{
${ }^{10}$ For a discussion of how we might restrict the imaginability principle to only a sub-class of imaginings, see Kung (2010).

${ }^{11}$ For discussion of the relationship between conceivability and possibility, see the papers collected in Gendler and Hawthorne 2002. The editors' substantive introduction provides an excellent overview of the relevant issues.
} 


\section{Concluding Remarks}

Our discussion thus far has suggested several loci of disagreement, and as such, it points to several avenues that are ripe further philosophical exploration. In these brief concluding remarks, I outline three questions that could usefully guide future philosophical research into imagination.

\section{Question 1: What is the relation between different kinds of imagining?}

As of yet, philosophers have not been successful at providing a unifying theory that captures the different kinds of imagination discussed in the literature. Indeed, many philosophers discussing imagination consider this task so difficult or futile that they have not even attempted it. To give just one example, having laid out many dimensions on which imaginings differ, Kendall Walton has noted in a much quoted passage: “[S]houldn't we now spell out what they have in common? Yes, if we can. But I can't." (Walton 1990, p. 19)

Above we discussed propositional vs. objectual imagination, but there are further debates about recreative vs. creative imagination, about experiential vs. non-experiential imagination, and so on. The debate about the relationship between imagination and conception is also relevant here. To make progress on our philosophical understanding of imagination, more attention needs to be paid as to whether the different kinds of imagination posited in the philosophical literature have something in common and, if so, what it is. If they do have something in common, then we should be able to ferret it out. And if they don't, then we should turn to the question of why - and indeed, whether - they should all be considered kinds of imagination.

Question 2: In what contexts is imagination really involved, and how can we tell?

We noted above that imagination has been invoked to do explanatory work in a great variety of philosophical contexts. In the absence of a clearer conception of what imagining is, however, it's hard to know whether the same kind of mental activity that's doing the explanatory work in one context is really the same on doing the explanatory work in another context- Is the mental activity that's involved when we engage with philosophical thought experiments the same mental activity as the one that's involved in games of pretense? Is it the same mental activity as the one that's involved in our engagement with fiction and in acts of creativity? (see Kind 2013 for a development of this worry). Moreover, the frequent invocation of imagination leads to further stretching of the notion. To give just one example, some philosophers have recently suggested that we can best explain delusions by developing an account of them that sees them as kinds of imagining. But since delusions seem in some sense more belief-like than the typical imagining, these same philosophers have been led to suggest that we should think of imagining and belief as on a continuum, where there is no sharp distinction between the two. Perhaps this is right, i.e., perhaps there is no sharp distinction between belief and imagination, but it is difficult to know exactly how to adjudicate the issue. One might wonder, for example, whether one would be better off abandoning the commitment to invoking imagination in this context rather than adopting a belief-imagination continuum account. Analogous issues arise in many other contexts.

Progress on Question 1 may help to alleviate this problem, but what is also needed is some attention to laying out a set of principled considerations for the invocation of imagination in different contexts.

Question 3: How does skill play a role in imagining? 
It's only very recently that philosophers in the Western analytic tradition have started to think seriously about skill; previously, this topic had been largely ignored or marginalized (e.g., Pavese 2016; Stanley and Williamson 2017). Understanding more clearly the notion of skill - and, more specifically, what it would be for imagination to be conceived as a skill - might help us make progress on questions about imaginability. Doing so could help us better understand why some scenarios have seemed unimaginable to some yet imaginable to others, and it could also help us adjudicate these debates. This in turn could lead to philosophical progress on the connection between imagination and possibility.

\section{References}

Balcerak Jackson, M. (2016). On the epistemic value of imagining, supposing, and conceiving. In Kind, A. and Kung, P. (Eds.), Knowledge through imagination (pp. 41-60). Oxford: Oxford University Press.

Brann, E. (1991). The world of imagination. Lanham, MD: Rowman \& Littlefield Publishers.

Byrne, R.M.J. (2005). The rational imagination: How people create alternatives to reality. Cambridge, MA: The MIT Press.

Churchland, P.S. (1998). The hornswoggle problem. In J. Shear (Ed.), Explaining consciousness: The hard problem (pp. 37-44). Cambridge, MA: The MIT Press.

Currie, G. \& Ravenscroft, I. (2002). Recreative minds. Oxford, Eng.: Oxford University Press.

Dennett, D. (1991). Consciousness explained. Boston, MA: Little, Brown and Company.

Descartes, R. (1641/1986). Meditations on first philosophy with selections from the objections and replies. Translated by John Cottingham. Cambridge: Cambridge University Press.

Doggett, T. and Egan, A. (2007). Wanting things you don't want: The case for an imaginative analogue of desire. Philosophers' Imprint, 7(9), 1-17.

Gendler, T. and Hawthorne, J. 2002. Conceivability and possibility. Oxford: Oxford University Press.

Gertler, B. (2007). In defense of mind-body dualism. In J. Feinberg and R. Shafer-Landau (Eds.), Reason and Responsibility (pp. 312-324). Boston, MA: Wadsworth.

Gettier, E. (1963). Is justified true belief knowledge? Analysis, 23(6), 121-123.

Goldman, A.I. (2006). Simulating minds: The philosophy, psychology, and neuroscience of mindreading. New York: Oxford University Press.

Hofstadter, D. (1979). Gödel, Escher, Bach: An eternal golden braid. New York: Random House Books.

Humberstone, I.L. (1992). Direction of fit. Mind 101(401), 59-83.

Hume, D. (1739/1985). A treatise of human nature. Edited by P.H. Nidditch. Oxford: Oxford University Press. 
Kind, A. (2016). Desire-like imagination. In A. Kind (Ed.), Routledge Handbook of Philosophy of Imagination, 163-176. London: Routledge.

Kind, A. Forthcoming. Imaginative experience. In U. Kriegel (Ed.), The Oxford Handbook of The Philosophy of Consciousness. Oxford: Oxford University Press.

Kind, A. (2001). Putting the image back in imagination. Philosophy and Phenomenological Research, 62(1), 85-109.

Kriegel, U. (2015) The varieties of consciousness. Oxford: Oxford University Press.

Kung, P. (2010). Imagining as a guide to possibility. Philosophy and Phenomenological Research, 81, 620-663.

McGinn, C. (2004). Mindsight. Cambridge, MA.: Harvard University Press.

Nanay, B. (2010). Perception and imagination: Amodal perception as mental imagery. Philosophical Studies, 150, 239-254.

Parfit, D. (1984). Reasons and persons. Oxford: Oxford University Press.

Pavese, C. (2016). Skill in epistemology I. Philosophy Compass, 11, 642-649.

Peacocke, C. (1985). Imagination, experience and possibility: A Berkeleian view defended." In J. Foster and H. Robinson (Eds.), Essays on Berkeley (pp. 19-35). Oxford, England: Clarendon Press.

Perky, C.W. (1910). An experimental study of imagination. American Journal of Psychology 21, 422-452.

Polyani, M. (1966/2009). Creative imagination. Reprinted in K. Bardsley, D. Dutton, and M. Krausz (Eds.), The Idea of Creativity (pp. 147-163). Leiden: Brill.

Rawls, J. (1971). A theory of justice. Cambridge, MA: Harvard University Press.

Sartre, J. (1936/1962). Imagination, translated by Forrest Williams. Ann Arbor, MI: The University of Michigan Press.

Sartre, J. (1940/2010). The imaginary, translated by Jonathan Webber. London: Routledge.

Shah, N. and Velleman, J.D. (2005). Doxastic deliberation. Philosophical Review, 114(4), 497-534.

Stock, K. (2017). Only Imagine. Oxford: Oxford University Press.

Stanley, J. and Williamson, T. (2017). Skill. Noûs, 51(4), 713-726.

Strawson, P.F. (1970). Imagination and perception. In L. Foster and J. W. Swanson (Eds.), Experience and theory, pp. 31-54. Amherst: University of Massachusetts Press (1970).

Thomson, J.J. (1971). A defense of abortion. Philosophy and Public Affairs, 1(1), 47-66.

Tidman, P. (1994). Conceivability as a test for possibility. American Philosophical Quarterly, 31(4), 297309.

Toon, A. (2012). Models as make-believe: Imagination, fiction, and scientific representation. Basingstoke: Palgrave Macmillan. 
White, A.R. (1990). The Language of Imagination. Oxford: Basil Blackwell. 